\title{
A humanização do parto no cenário de disputas da obstetrícia
}

MAIA, Mônica Bara.

\section{Humanização do parto: política pública, comportamento organizacional} e ethos profissional.

Rio de Janeiro: Fiocruz, 2010. 189 p.

\section{| ${ }^{1}$ Antonio Rodrigues Ferreira Júnior, ${ }^{2}$ Nelson Filice de Barros | \\ 1 Universidade Estadual de Campinas. Endereço eletrônico: junioruruoca@hotmail.com \\ 2 Universidade Estadual de Campinas. Endereço eletrônico: nelfel@uol.com.br}

A busca por melhora da qualidade na assistência ao parto e nascimento no Brasil é um desafio para os profissionais de saúde, considerando-se os elevados índices atuais de mortalidade materna e infantil encontrados. Políticas públicas têm sido implantadas visando otimizar o suporte na área, exemplificadas pelo lançamento da Rede Cegonha, que surge como estratégia do Governo Federal para aumentar o acesso e qualificar a atenção à saúde dos envolvidos no processo gravídico-puerperal. Neste âmbito, discussões sobre a temática possuem relevância por envolverem questóes técnicas e políticas que demandam constante aprimoramento das práticas de saúde desenvolvidas pelos profissionais envolvidos com a obstetrícia.

O livro Humanização do parto: politica pública, comportamento organizacional e ethos profissional, de Mônica Bara Maia, que provém de sua dissertação de mestrado, defendida no Programa de Pós-graduação em Ciências Sociais da Pontifícia Universidade Católica de Minas Gerais, analisa o modelo de assistência ao parto no Brasil e o processo de humanização na área.

Nos dois primeiros capítulos, as reflexões sobre a assistência à saúde e ao parto no Brasil são promovidas por meio de narrativa temporal, que ambienta essa assistência desde os tempos de Colônia até a implantação do Sistema Único de Saúde (SUS). Esta reconstrução histórica explicita a institucionalização do parto no sistema de saúde brasileiro como prática que evoluiu concomitantemente ao desenvolvimento da própria obstetrícia na formação médica no mundo. Além 
disso, mostra como o parto se tornou medicalizado e hospitalar, inaugurando o modelo tecnocrático de assistência, influenciado pelos símbolos iluministas do corpo como máquina e do médico como mecânico. Da mesma forma, a mulher perdeu o papel de protagonista do processo de gestação e parto, sendo o médico promovido como responsável pela condução ativa de todo o processo.

A autora deixa ver, assim, que neste modelo se realiza uma associação dos hospitais com as linhas de produção tayloristas, segundo as quais a mulher é submetida passivamente a diversos procedimentos invasivos, ditos necessários para a prática da boa medicina. Na mesma lógica, o conceito de cesárea torna-se padrão ouro de atenção dispensada à mulher, potencializando forte rede hospitalar, oriunda dos vultosos investimentos públicos e privados. Neste contexto, emerge a humanização do parto como movimento de contracultura, visando devolver à mulher seu papel de protagonista durante o período gestacional e parto com menor intervenção. Com isso, o parto no país passa a ser campo de disputa política. Surgem disputas de poder entre médicos e enfermeiros obstetras, visto que o modelo tecnocrático é centrado no primeiro e as políticas de humanização buscam legitimar o segundo, na condução de ações durante o parto normal sem complicações. De tal modo, a obstetrícia como campo de atuação de médicos e enfermeiros começa a crescer em relevância para a enfermagem, principalmente pelo apoio normativo e político do Ministério da Saúde.

No terceiro capítulo, a autora utiliza o exemplo do município de Belo Horizonte-MG para discutir a humanização do parto como mecanismo fortalecedor do paradigma que potencializa os preceitos do SUS, agregando profissionais em equipe e estimulando a inclusão de novos atores, como as doulas e os acompanhantes. No entanto, ela é dificultada pela tecnologia, tida como símbolo positivo na sociedade atual. Dessa forma observam-se, por um lado, campos de conflitos na prática cotidiana da assistência obstétrica; por outro, possibilidades de melhora no monitoramento da qualidade da assistência, ainda menos aceito em instituições privadas conveniadas ao SUS. Produz-se, assim, um cenário peculiar na saúde suplementar que desestimula a humanização do parto, pela configuração de poderes especiais ao médico obstetra na tomada de decisões desde o pré-natal. Nele as mulheres estão mais expostas ao modelo tecnocrático de assistência, que reforça a perda de seu protagonismo ou coadjuvância no processo. Por isso, ações de humanização devem acontecer também durante a formação 
médica, para que se construa a ideia de parto como momento fisiológico, em que o cuidado deve sobressair, e não algo patológico, passível de tratamento ou mecanismos de cura.

No quarto capítulo, Mônica Maia discorre acerca da importância dos estabelecimentos hospitalares para a implementação da humanização na área obstétrica. Ela analisa a rede de saúde terciária de Belo Horizonte-MG, remetendo a questôes complexas como custo hospitalar do parto e relaçôes de trabalho. Mostra, ainda, como as parcerias iniciadas em 1994 entre o setor público de saúde e integrantes da sociedade levaram à melhora da assistência ao parto e nascimento na capital mineira.

O livro é finalizado com um anexo que relata o parto vivenciado por uma mulher que foi protagonista do processo e torna clara a importância da humanização para a melhora da qualidade da assistência obstétrica.

Esse trabalho consegue fomentar discussões sobre as práticas de humanização no campo da obstetrícia, sendo adequado para disparar ressignificações profissionais, com o fim de implementar a humanização nos serviços de saúde brasileiros. Ele retrata um cenário de disputas de poder no campo da obstetrícia, vivenciado por enfermeiros e médicos obstetras no cotidiano de suas práticas. No entanto, apontamos a necessidade de maior aprofundamento desta discussão na formação dos profissionais obstetras brasileiros, visando otimizar o entendimento sobre a autonomia dos principais envolvidos na área, com práticas que assegurem os direitos da mulher e de sua família. ${ }^{1}$

\section{Nota}

${ }^{1}$ Os autores participaram igualmente de todas as etapas de elaboração desta resenha. 